\title{
Improvement of the Method for Calculating the Metal Temperature Loss on a Coilbox Unit at The Rolling on Hot Strip Mills
}

\author{
Volodymyr Kukhar $^{1 *}$, Oleksandr Kurpe ${ }^{2}$, Eduard Klimov ${ }^{3}$, Elena Balalayeva ${ }^{1}$, Vladimir Dragobetskii ${ }^{3}$ \\ ${ }^{1}$ Pryazovskyi State Technical University \\ ${ }^{2}$ METINVEST HOLDING, LLC, Mariupol, Ukraine \\ ${ }^{3}$ Kremenchuk Mykhailo Ostrohradskyi National University \\ Corresponding author E-mail: kvv.mariupol@gmail.com
}

\begin{abstract}
The paper improves the calculation methodology of metal temperature loss during hot rolling process at continuous mills. The proposed methodology can be implemented at hot strip mills with various in-line equipment arrangements within the temperature ranges appropriate for processes simulation of hot rolling, normalized rolling and Thermo-Mechanical Control Process of carbon and microalloyed steels It provides engineering analysis of unaccounted temperature losses of feed by means of radiation and convection, which, in the first time, through the time factor, additionally accounts for strip motion speed factors, roller table length and feed length, and also length of rolls contact arc with metal. The accountability of the above mentioned factors in the various compositions depending on the rolling method increases the engineering simulation accuracy, ensures the versatility of the elaborated method with respect to different types of mills and makes the scientific novelty of the study. The equations were developed to calculate the metal temperature loss while coiling at the CoilBox unit. The equations accounts for the influence on the temperature of strip length, coiling and uncoiling speed, strip thickness, inside radius of the reeling coil, the time the feed rests being coiled. The improved model was verified based on actual data.
\end{abstract}

Keywords: CoilBox; Flat products; Hot strip rolling mill; Rolling; Simulation; Temperature conditions

\section{Introduction}

Market requirements for expanding the range of hot-rolled coils is necessitate the development of new technologies applied to broadband (wide-strip) hot rolling mills. The typical examples of such hot strip rolling mills are technological plants 1680 of PJSC " $\mathrm{Za}-$ porizhstal" (Zaporizhzhia, Ukraine) and 1700 of PJSC "Ilyich Iron and Steel Works of Mariupol" (Mariupol, Ukraine), working in METINVEST HOLDING Group. Designing of the technology before its implementation on existing equipment, the identification of problem areas and provision of occupational safety conditions for employees [1] is possible using of mathematical simulation tools of the processes an important component of which is the calculation of the temperature of rolling. The development of such a tool, taking into account the features of the equipment of the 1680 and the 1700 rolling mills, will allow to evaluate their technical capabilities and expand the assortment, including those produced using the Thermo-Mechanical Control Process (TMCP) technology.

The simulation of the hot deformation temperature conditions has been extensively studied by the authors of [2-16]. The proposed solutions are aimed both at specific sets of rolling equipment, and laboratory samples of the mills. The universality of the existing mathematical models and the possibility of their application for the calculation of rolling plants with different composition of the basic technological equipment are remains questionable.

The important point noted in works $[2,17,18]$ is the need to obtain accurate models for designing a controlled rolling technology for microalloyed steel grades. Also, the importance of accurate temperature determination was noted by the authors $[3,4,15,18$ $21]$ in order to ensure the required cooling rate, structure, mechanical properties and other quality characteristics of rolled products. It should be noted that in works [2-4, 8, 22, 23] the authors studied discrete deformation processes without reference to specific production complexes. At the same time, in [5], the authors propose calculations and justify the use of different designs of process equipment with the CoilBox unit, as well as with the induction furnace, which allows further increasing the temperature and reducing the load on the rolling mill. Thus, in [10], the authors describe a method for calculating the temperature loss at the CoilBox unit that takes into account the loss at each turn. This method is of interest, however, the method itself or the dependence in the work are not given. It is also necessary to check the error obtained by using this method, since the total error of the model is more than $6 \%$. At the same time, the authors investigated the technology in a wide range of temperatures, including in the two-phase region, which makes it possible to apply the model for low-temperature controlled rolling processes.

General accuracy of mathematical models developed by different scientists varies due to the different structure of models, approaches and methods of calculation. Thus, the authors of paper [9] proposed an adapted method of calculation, which error does not exceed $3.4 \%$ for the stands, compared with the unadapted, which error was up to $6 \%$ from the actual data by the rolling force. In paper [10] the total error of the model is also determined by calculating the rolling force. 
The authors of papers $[4,11,24]$ proposed a temperature changing model, the error of which is defined in Celsius $\left({ }^{\circ} \mathrm{C}\right)$ or Kelvin $(\mathrm{K})$ degrees. Thus, the temperature deviation in [4], determined by two methods, is $4.2^{\circ} \mathrm{C}$, in [11] the temperature deviation on the surface of the two experimental sheets was from $-20^{\circ} \mathrm{C}$ to $+10^{\circ} \mathrm{C}$ and from $+10^{\circ} \mathrm{C}$ to $+30^{\circ} \mathrm{C}$, respectively.

In [13], the authors investigated the influence of velocity processes on the temperature drop along the strip length, taking into account the coiling at the CoilBox unit, but the dependence itself is not given. The authors assumed also that the temperature of the metal that is coiled does not change. At the same time, the dependences for the determination of the temperature loss when looking at CoilBox, based on the differential equation of thermal conductivity, are given in [25]. These equations do not take into account the loss of temperature during coiling uncoiling, which limits their application.

Thus, the existing dependencies and methods for calculating temperature loss in CoilBox unit are simplified; they do not take into account some important factors and do not provide the necessary accuracy of calculations. The information available in the literature is not sufficient for a universal mathematical description of metal cooling processes in CoilBox unit. Calculations performed by engineering companies have limited access. The existing limitations necessitate the development of dependencies for a wide application in engineering calculations of rolling temperature processes in conjunction with CoilBox equipment.

The relevance of these calculations is due to the use of CoilBox equipment at PJSC "Zaporizhstal", as well as its installation during the forthcoming renovation of the 1700 mill of PJSC "Ilyich Iron and Steel Works of Mariupol".

\section{The purpose of the Work}

The purpose of the work is to refine the method for calculating the temperature loss of metal with using CoilBox equipment, taking into account the velocity factor of the strip, the length of the roller table and the length of the roll, applied to the conditions of hot strip rolling mills of the PJSC "Zaporizhstal" and PJSC "Ilyich Iron and Steel Works of Mariupol".

\section{Methodology and Research}

A typical model for calculating hot rolling mills includes the following steps $[6,7]$ :

1. Calculation of the dimensions of the initial workpiece, which includes calculation of the specific metal consumption for rolling, recalculation of the dimensions of the workpiece into the hot state;

2. Calculation of energy-force parameters of rolling includes calculation of the rolling temperature conditions, coefficient of friction, actual strain resistance, strength and rolling moment;

3. Calculation of speed rate of the rolling includes the calculation of the rolling time, depending on the type of speed rate, the rolling cycle;

4. Calculation of the mean square torque of the motor consists of calculating the moments for each rolling cycle, the root mean square (rms) integral and the rolling mill motor power.

The principles outlined in this calculation structure are universal and can be applied to simulating the technology in various hot rolling mills. In this paper the simulation features of hot rolling technology on continuous strip mills are considered using the example of the 1700 mill equipment of PJSC "Ilyich Iron and Steel Works of Mariupol", taking into account the renovation project (positions 8 and 9), Fig. 1. A typical design of a continuous hot rolling mill, using the example of the 1700 mill of PJSC "Ilyich Iron and Steel Works of Mariupol" is shown in Fig. 1.

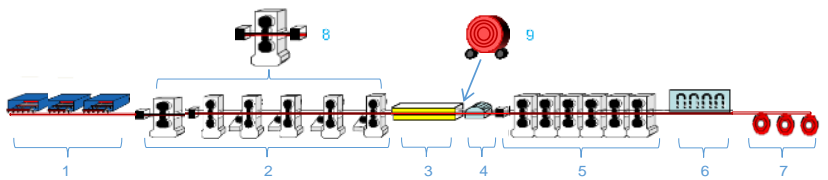

Fig. 1: The layout of the 1700 rolling mill main equipment: (1) a section of methodical furnaces; (2) a roughers (roughing stands group); (3) heatshielding screens; (4) flying shear; (5) finishers (finishing stands group); (6) accelerated cooling; (7) coilers; (8) reversing rougher; (9) CoilBox unit

The main technological equipment of continuous mills can consist of one or several universal reversing stands or a combination of reversing and non-reversing instead of an irreversible roughing group, intermediate coiling equipment such as CoilBox before the finishing group, other variants are also possible.

Calculation of rolling temperature conditions takes into account the following factors $[3,4,6-8,11,13,19]$ :

1. Reducing the feed temperature due to temperature loss by radiation;

2. Temperature loss by convection;

3. Temperature loss due to contact of metal with rollers;

4. Temperature drop due to temperature loss during the hydraulic descaling;

5. Increase in the feed temperature due to the energy of deformation.

In non-reversing stands of roughing and finishing groups, the total time spent on temperature loss by radiation and convection is determined by the dependence:

$\tau_{\Sigma}=\tau+\tau_{t}$,

where $\tau$ is the time spent for rolling feed in the stand, sec; $\tau_{t}$ is the transporting time of the feed between the roughers, sec. When calculating the finishing group, in equation (1) the parameter $\tau_{t}$ is replaced by $\tau_{t 1}$ - the transporting time of the feed between the finishers, sec;

Wherein for the roughing group, where rolling is carried out successively in each stand the time spent on rolling $\tau$ is determined by calculating the speed rate of rolling $[6,7]$.

The transportation time of the feed between the roughers is determined by the dependence:

$\tau_{t}=\left(l_{r}-l\right) / v_{r}$,

where $v_{r}$ is strip motion speed on a roller table, $\mathrm{m} / \mathrm{sec} ; l_{r}$ is roller table length, $\mathrm{m} ; l$ is feed length, $\mathrm{m}$, provided that $l_{r}>l$.

For the finishing group, where rolling is carried out simultaneously in several stands, the time spent for rolling in the cage is considered by the equation:

$\tau=l_{g} /\left(v_{\text {roll }} \cdot 1000\right)$,

where $l_{g}$ is the contact arc length, $\mathrm{mm} ; v_{\text {roll }}$ is the rolling speed, $\mathrm{m} / \mathrm{sec}$.

The time of transportation of the feed between the finishers is determined by the dependence:

$\tau_{t 1}=l_{r} / v_{\text {roll }}$,

Calculation of the metal temperature loss during feed coiling at the CoilBox unit can be determined from Yu.V. Konovalov's equation [7]:

$\Delta t=k_{u k}\left(\left(t_{0}+273\right) / 100\right)^{4} \cdot \tau_{c} / h_{c}$, 
where $h_{c}$ is the roll thickness, $\mathrm{mm} ; t_{0}$ is feed temperature when arriving at CoilBox unit, ${ }^{\circ} \mathrm{C} ; \tau_{c}$ is length of the procedures, sec; $k_{u k}$ is the coefficient found by the graph [7].

Having transformed the graph [7] to determine the coefficient, we obtain the dependence, Fig. 2:

$$
k_{u k}=\left(2.0284 \ln \left(t_{0}\right)-12.195\right) / 1000 .
$$

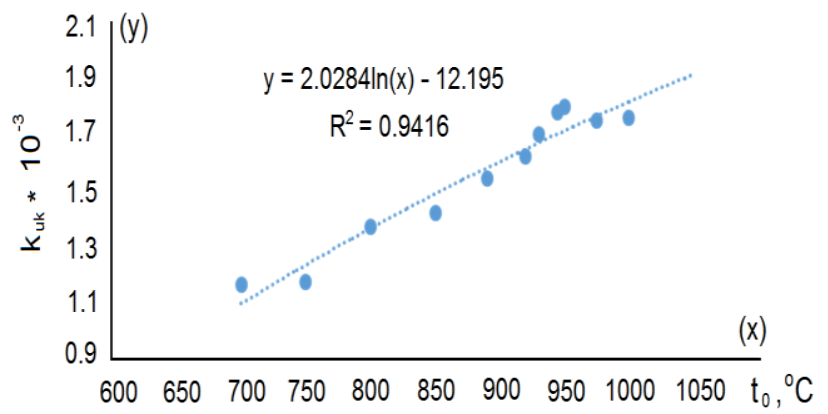

Fig. 2: The dependence of the coefficient $k_{u k}$ on the pre-rolled metal temperature.

Taking into account the dependence (6), the equation for calculating the temperature loss of the feed after the CoilBox unit is:

$\Delta t_{1}=\frac{2.0284 \ln \left(t_{0}\right)-12.195}{1000} \cdot \frac{\left(\tau_{c} / h_{c}\right) \cdot\left(t_{0}+273\right)}{100^{4}}$.

The technological operation duration of coiling and uncoiling of the roll is defined as follows:

$$
\tau_{c}=L /\left(v_{w} \cdot 1000\right)+L /\left(v_{u w} \cdot 1000\right)+\tau_{p}
$$

where $L$ is length of the feed, $\mathrm{mm} ; v_{w}$ is coiling speed, $\mathrm{m} / \mathrm{sec}$; $v_{u w}$ is uncoiling speed, $\mathrm{m} / \mathrm{sec} ; \tau_{p}$ is time the coiled roll spends at the facility, sec.

The roll thickness is determined from the equation:

$H \cdot B \cdot L \cdot \rho=\left(\pi R^{2}-\pi r^{2}\right) \cdot B \cdot \rho$,

where $H, B, L$ are thickness, width and length of coiled feed, mm; $\rho$ is density of steel, $7.85 \mathrm{~g} / \mathrm{cm}^{3} ; R$ is the outer radius of the roll after coiling at the CoilBox unit, $\mathrm{mm} ; r$ is the inner radius of the roll, according to the facility characteristics, $\mathrm{mm}$.

After the transformation of equation (9), we obtain the dependence for determining the outer radius of the roll:

$$
R=\sqrt{(H \cdot L) / \pi+r^{2}} \text {. }
$$

Roll thickness obtained after coiling is calculated:

$$
h_{c}=\left(\sqrt{(H \cdot L) / \pi+r^{2}}-r\right) \cdot 1.05 \text {. }
$$

where 1.05 is coiling looseness ratio.

Taking into account the dependences (8) and (11), the equation for calculating the temperature loss of the feed after the CoilBox unit turns into:

$$
\Delta t_{1}=\frac{2.0284 \ln \left(t_{0}\right)-12.195}{1000} \cdot \frac{L /\left(v_{w} \cdot 1000\right)+L /\left(v_{u w} \cdot 1000\right)}{\left(\sqrt{(H \cdot L) / \pi+r^{2}}-r\right) \cdot 1.05} \cdot \frac{t_{0}+273}{100^{4}} \text {. }
$$

It should be noted that the obtained dependence takes into account the temperature loss of the metal at steady state of a coiled roll. To account for additional temperature loss of the metal from unrecorded factors (the influence of feed thickness, the temperature loss at the initial stage of coiling and at the end of uncoiling, the influence of "thermos" effect when the rolled products rests at coiled state), we processed the calculation data of "Primetals" company, Fig. 3.

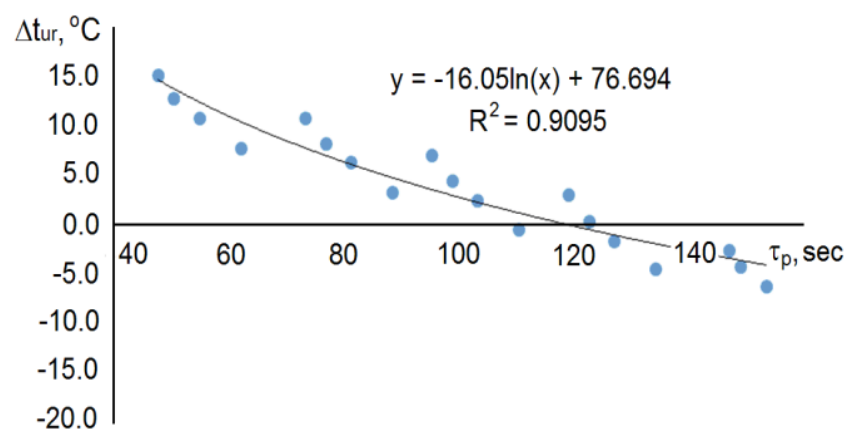

Fig. 3: The dependence of temperature losses on unaccounted factors, expressed through $\tau_{p}$.

As a result of data processing, the following dependence was obtained for determining the temperature loss from unrecorded factors:

$\Delta t_{u r}=-16.05 \ln \left(\tau_{p}\right)+76.694$

Thus, taking into account dependence (13), the total temperature loss of the metal after the CoilBox unit is determined:

$\Delta t_{\Sigma}=\Delta t_{1}+\Delta t_{u r}$

Changes of the metal temperature at the CoilBox facility depending on the cooling time (speed change of coiling/uncoiling) and a formed roll thickness, all other things being equal, obtained using dependence (14) are shown in Fig. 4.

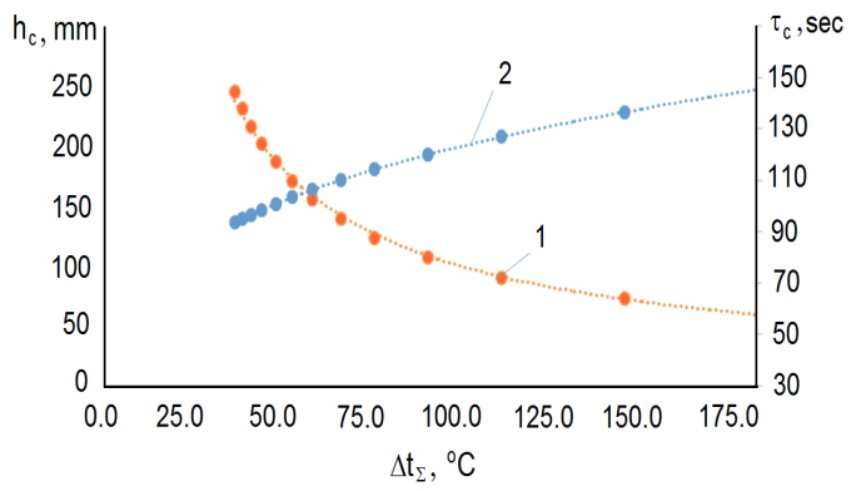

Fig. 4: The dependences of temperature losses on the thickness of coiled roll (1) and cooling time (2).

\section{Results and Application}

The equations obtained (12-14) are applicable in the temperature range $700-1100{ }^{\circ} \mathrm{C}$, coiled metal cooling time on the facility being $30 \mathrm{sec}$ to $1000 \mathrm{sec}$, for carbon and microalloyed steels. To verify the results of calculations in other ranges, additional research is required.

The verification of the dependence (14) was carried out on the data obtained by the authors of [4]. The deviation of the metal design temperature at the exit from CoilBox from the actual temperature was $-4.2 \%$ to $-6.4 \%$, Table 1 (in Table $1 t_{1}=t_{0}-t_{\Sigma}$ is metal temperature at the exit from the CoilBox, ${ }^{\circ} \mathrm{C}$ ). 
The deviations obtained may be due to the lack of information on additional loss factors and the location of pyrometers for temperature measurements.

Table 1: Checking the dependence for determining the metal temperature loss at coiling at the CoilBox unit

\begin{tabular}{|c|c|c|c|}
\hline${ }^{*} r, \mathrm{~mm}$ & 700 & 700 & 700 \\
\hline$t_{0},{ }^{\circ} \mathrm{C}$ & 1096 & 1018 & 1053 \\
\hline$L, \mathrm{~mm}$ & 64558 & 243417 & 228437 \\
\hline$v_{w}, \mathrm{~m} / \mathrm{sec}$ & 2.2 & 6.5 & 6.5 \\
\hline$v_{u w}, \mathrm{~m} / \mathrm{sec}$ & 1.79 & 6.25 & 6.25 \\
\hline$\tau_{p}, \mathrm{sec}$ & 70 & 70 & 70 \\
\hline$H, \mathrm{~mm}$ & 23 & 6.1 & 6.5 \\
\hline$t_{1}(\mathrm{actual}),{ }^{\circ} \mathrm{C}$ & 992 & 942 & 965 \\
\hline$h_{c}, \mathrm{~mm}$ & 295.2 & 295.2 & 295.2 \\
\hline$\Delta t_{\Sigma}$ (actual), ${ }^{\circ} \mathrm{C}$ & 104.0 & 76.0 & 88.0 \\
\hline$\tau_{c}, \mathrm{sec}$ & 135.4 & 146.4 & 141.7 \\
\hline$\Delta t_{\Sigma}($ design$),{ }^{\circ} \mathrm{C}$ & 41.0 & 36.4 & 38.6 \\
\hline$t_{1}($ design $),{ }^{\circ} \mathrm{C}$ & 1055.0 & 981.6 & 1014.4 \\
\hline$\Delta, \%$ & -6.4 & -4.2 & -5.1 \\
\hline
\end{tabular}

* data not available in [5], were adopted according to the characteristics of similar equipment at PJSC "Zaporizhstal”.

Also, the verification was performed on the calculation data of "Primetals" company. The deviation of the metal temperature at the exit from the CoilBox, determined from dependence (14), on the calculation data of "Primetals" company was from $-0.91 \%$ up to $0.39 \%$. The standard deviation was $2.95^{\circ} \mathrm{C}$.

Checking the accuracy of calculating the rolling temperature conditions with the equations $(1-4)$ is performed on a mathematical model [5], adapted for the conditions of the continuous hot strip (broadband) rolling mill 1700 of PJSC "Ilyich Iron and Steel Works of Mariupol", Table 2 (in Table $2 t_{1}$ is the feed temperature after rolling in the corresponding rolling stand).

Table 2: Checking the calculation of rolling temperature conditions

\begin{tabular}{|c|c|c|c|c|c|}
\hline \multirow{2}{*}{ Parameter } & $\begin{array}{c}\text { Roughing } \\
\text { group }\end{array}$ & \multicolumn{4}{|c|}{ Finishing group } \\
\cline { 2 - 6 } & \multicolumn{5}{|c|}{ Rolling stand No. } \\
\cline { 2 - 6 } & $4 \mathrm{a}$ & 6 & 7 & 8 & 9 \\
\hline $\begin{array}{c}t_{1} \\
(\text { design), } \\
{ }^{\circ} \mathrm{C}\end{array}$ & 1068 & 972 & 932 & 885 & 854 \\
\hline $\begin{array}{c}t_{1} \\
(\text { actual), } \\
{ }^{\circ} \mathrm{C}\end{array}$ & 1075 & 963 & 921 & 874 & 845 \\
\hline $\begin{array}{c}\Delta, \\
\%\end{array}$ & -0.66 & 0.89 & 1.19 & 1.21 & 1.1 \\
\hline
\end{tabular}

The deviations of the design temperatures of the feed from the actual ones in the roughing stand $4 \mathrm{a}$ and in the finishing stands 6-9, according to the results of hot-rolled coils of the size $1.2 \times 1000 \mathrm{~mm}$ from the $08 \mathrm{pc}$ steel grade in accordance with GOST 9045 (analogue DC01 to EN 10130), melting No.262753-3 amounted from $-0.66 \%$ to $1.21 \%$.

Thus, the accuracy of the improved calculation of the rolling temperature conditions, including using CoilBox equipment, allows it to be used in the design of TMCP technology.

\section{Conclusions}

In this paper, the specifics of calculating the time spent on temperature loss by radiation and convection on continuous hot strip rolling mills, successive or simultaneous in several stands are refined. The error in calculating the rolling temperature conditions on the basis of the actual data for the 1700 hot rolling (broadband) mill of PJSC "Ilyich Iron and Steel Works of Mariupol" (Mariupol, Ukraine) was from $-0.66 \%$ to $1.2 \%$.

A dependence has been developed to determine the temperature loss of the feed when coiling at the CoilBox unit, which accounts for the influence of coiling and uncoiling speed, the time the feed rests being coiled, and additional losses, such as the influence of the strip thickness, the metal temperature loss at the initial stage of coiling and at the end of the uncoiling, the "thermos" effect when resting the rolled product in coiled state. The error of the proposed dependence was verified on various data and ranged from $-0.91 \% / 0.39 \%$ to $-4.2 \% /-6.4 \%$.

\section{References}

[1] Kukhar V., Yelistratova N., Burko V., Nizhelska Yu., \& Aksionova O., "Estimation of occupation safety risks at energetic sector of Iron and Steel Works", International Journal of Engineering \& Technology (UAE), Vol.7, No.2.23, (2018), pp.216-220, https://doi.org/10.14419/ijet.v7i2.23.11922.

[2] Kim J., Lee J., \& Hwang S.M., “An analytical model for the prediction of strip temperatures in hot strip rolling", International Journal of Heat Mass Transfer, No.52, (2009), pp.1864-1874, https://doi.org/10.1016/j.ijheatmasstransfer.2008.10.013.

[3] Kiuchi M., Yanagimoto J., \& Wakamatsu E., "Overall Thermal Analysis of Hot Plate/Sheet Rolling", CIRP Annals - Manufacturing Technology, Vol.49, Issue 1, (2000), pp.209-212.

[4] Moon C.H., \& Lee Y., "An approximate method for computing the temperature distribution over material thickness during hot flat rolling”, International Journal of Heat and Mass Transfer, Vol.55, Issue 1-3, (2012), pp.310-315, https://doi.org/10.1016/j.ijheatmasstransfer.2011.09.019.

[5] Vasilyev A.A., \& Nikolaev V.A., "New technology for hot rolling of wide-strip steel", Cherepovets State University Bulletin, No.4(2), (2013), pp.5-10, in rus.

[6] Kurpe A.G. Simulation of the technological process for plates rolling at rolling mill 3600 of Azovstal Iron and Steel Works, Extended abstract of dissertation PhD in Technical Sciences (05.16.05), Federal State Unitary Enterprise (FSUE) I.P. Bardin Central Research Institute for Ferrous Metallurgy, Moscow, (2006), 23p., in rus.

[7] Konovalov Yu.V., Ostapenko A.L., \& Ponomarev V.I., Calculation of sheet rolling parameters: Reference book, Moscow, Metallurgy, (1986), 430p., in rus.

[8] Pal S.K., \& Linkens D.A., "Temperature distribution in steel during hot rolling: pseudo-bond graph view", Simulation Modelling Practice and Theory, Vol.10, Issue 1-2, (2002), pp.69-85, https://doi.org/10.1016/S1569-190X(02)00060-6.

[9] Peng W., Liu Z., Yang X., Cao J., \& Zhang D., "Optimization of Temperature and Force Adaptation Algorithm in Hot Strip Mill", Journal of Iron and Steel Research, International, Vol.21, Issue 33, (2014), pp.300-305, https://doi.org/10.1016/S1006706X(14)60046-7.

[10] Phaniraj M.P., Behera B.B., \& Lahiri A.K. "Thermo-mechanical modeling of two phase rolling and microstructure evolution in the hot strip mill: Part I. Prediction of rolling loads and finish rolling temperature", Journal of Materials Processing Technology, Vol.170, Issue 1-2, (2005), pp.323-335 https://doi.org/10.1016/j.jmatprotec.2005.05.009.

[11] Speicher K., Steinboeck A., Wild D., Kiefer T., \& Kugi A., "Estimation of plate temperatures in hot rolling based on an extended Kalman filter", IFAC Proceedings Volumes, Vol.46, Issue 16, (2013), pp.409-414, https://doi.org/10.3182/20130825-4-US2038.00006.

[12] Sui F., Chen L., Liu X., Wang L., \& Li W., "Temperature field analysis and its application in hot continuous rolling of Inconel 718 superalloy", Acta Metallurgica Sinica (English Letters), Vol.22, Issue 2, (2009), pp.81-90, https://doi.org/10.1016/S10067191(08)60074-5.

[13] Konovodov D.V., Mokievec A.V., \& Kuzmina O.M., "Investigation of the influence of the speed range of operation between roughing and finishing rolling mill stand groups using an intermediate recoiling device of the "CoilBox" type on the temperature distribution along the length of the rolling strip", Plastic Deformation of Metals, Dnipropetrovsk, Akcent PP, Vol.1, (2014), pp.39-43, in rus., available online: http://www.metal-forming.org/images/statti/conf2014/tom-1.pdf 
[14] Kukhar V., Artiukh V., Serduik O., \& Balalayeva E., "Form of gradient curve of temperature distribution of lengthwise the billet at differentiated heating before profiling by buckling", Procedia Engineering, Vol.165, (2016), pp.1693-1704, http://dx.doi.org/10.1016/j.proeng.2016.11.911.

[15] Kukhar V., Prysiazhnyi A., Balalayeva E., \& Anishchenko O., "Designing of induction heaters for the edges of pre-rolled wide ultrafine sheets and strips correlated with the chilling end-effect", Modern Electrical and Energy System (MEES'2017), IEEE, Kremenchuk, Ukraine, (2017), pp.404-407, http://doi.org/10.1109/MEES.2017.8248945.

[16] Belevitin V., Smyrnov Y., Kovalenko S., Suvorov A., \& Skliar V. "Modeling of the energy potential saving in the production of seamless pipes", Journal of Chemical Technology \& Metallurgy, Vol.52, Issue 4, (2017), pp.718-723, available online: http://dl.uctm.edu/journal/node/j2017-4/17_16-43_Smyrnov_718723.pdf.

[17] Endo S., \& Nakata N., "Development of thermo-mechanical control process (TMCP) and high performance steel in JFE Steel", JFE Technical Report, No.20, (2015), pp.1-7, available online: www.jfe-steel.co.jp/en/research/report/020/pdf/020-02.pdf.

[18] Gorni A.A. \& Cavalcanti C.G., "Modeling the Controlled Rolling Critical Temperatures Using Empirical Equations and Neural Networks.", 7th International Conference on Steel Rolling, The Iron and Steel Institute of Japan, Chiba, (2006), pp.629-633.

[19] Nishioka, K., \& Ichikawa, K. "Progress in thermomechanical control of steel plates and their commercialization", Science and Technology of Advanced Materials, Vol.13(2), (2012), 023001, http://doi.org/10.1088/1468-6996/13/2/023001.

[20] Kukhar V., Artiukh V., Prysiazhnyi A. \& Pustovgar A., "Experimental Research and Method for Calculation of 'Upsetting-withBuckling' Load at the Impression-Free (Dieless) Preforming of Workpiece", E3S Web of Conference, Vol.33, (2018), 02031, https://doi.org/10.1051/e3sconf/20183302031.

[21] Minaev A.A., Nosanev A.G., Smirnov E.N., Bublik P.F. \& Shishkevich V.V., "Unit for accelerated cooling of reinforcement bars in the line of a 330 mill after deformation", Metallurgist, Vol.34, Issue 1, (1990), p.17.

[22] Grushko A.V., Kukhar V.V., \& Slobodyanyuk Yu.O., "Phenomenological Model of Low-Carbon Steels Hardening during Multistage Drawing", Solid State Phenomena, Vol.265, (2017), pp.114123, https://doi.org/10.4028/www.scientific.net/SSP.265.114.

[23] Sorokatyi R.V., \& Dykha A.V., "Analysis of processes of tribodamages under the conditions of high-speed friction", Journal of Friction and Wear, Vol. 36(5), (2015), pp.422-428, https://doi.org/10.3103/S106836661505013X.

[24] Gupta Y.C., Bansal K., \& S.N. Sriniwas, "Secondary steel mill furnace performance", International Journal of Engineering \& Technology (UAE), Vol.7, No.2.6, (2018), pp.102-106, http://dx.doi.org/10.14419/ijet.v7i2.6.10076.

[25] Konovodov D.V., Karakash E.O., Mokievec O.V., \& Panchenko V.S. "Studies of changes in the intermediate temperature of the strip rewinder for broadband hot rolling mill", Materials Working by Pressure, Vol.3(36), (2013), pp.160-164, in rus. 